\section{Drug Treatment of Cancer}

Dr. G. R. Usmar (Boston, Lincs) writes: With reference to the most interesting answer under this heading (Aug. 25, p. 271) on Oct. 17, 1944 , I saw a patient suffering from a large fungating cancer of the right breast; operative treatment and radium, etc., were refused. She was given stilboestrol $1 \mathrm{mg}$. t.d.s. Within one week bleeding ceased. The district nurse noted that skin was beginning to appear around the edges. By January the skin had been completely reformed. The general health of the patient was greatly improved. This was probably due to the external appearance of the cancer, for she did not gain weight, though her appetite had vastly improved. In May, 1945, she began to deteriorate in health, and in June, 1945, she died of cachexia due to secondaries in both lungs and secondaries in thoracic vertebrae. However, this drug treatment was most beneficial from the patient's point of view, and she was most happy in her last year. Of course I made a point of informing the relatives of the ultimate outcome (for they were inclined to hail stilboestrol as a miracle).

\section{Constriction Ring}

Lieut.-Col. F. R. W. K. Allen writes from the Indian Military Hospital, Poona: It appears from a case reported in the American Journal of Obstetrics and Gynecology, November, 1943, that adrenaline may sometimes relax a constriction ring of the uterus. Deep chloroform or ether anaesthesia may have a similar effect, but the rural practitioner may only have chloroform at his disposal. Vinesthene is alleged to have much less relaxing power on the uterus than chloroform. The pharmacologists tell us that a combination of adrenaline by injection and choloroform by inhalation is liable to induce auricular fibrillation. A number of textbooks on obstetrics recommend both injections of adrenaline and deep chloroform anaesthesia in the treatment of constriction-ring dystocia where delivery has become imperative. Is there really danger in a combination of adrenaline injections and deep chloroform anaesthesia in such a case? Could amphetamine (methedrine) be substituted for adrenaline to safeguard the parturient from the danger of auricular fibrillation without a reduction in the relaxation of the constriction ring? I have only once felt a constriction ring, and that was of a mild degree. After a forceps delivery I was waiting for the birth of the placenta. There was no haemorrhage, but we wished to return the patient to her bed and have the delivery table ready for the next case. I tried gentle expression without avail, so I passed my hand into the uterus and found a constriction ring about half-way between the external "os" and the fundus. The placenta was lying free above the ring and there was no difficulty in drawing it out. The parturient was not injured by either of my operations.

\section{Ptyalism in Pregnancy}

Dr. W. H. Nelson (Perth, Western Australia) writes: In the Journal of April 14 (p. 543) there was a query about ptyalism in pregnancy. Many years ago I attended a pregnant woman suffering from vomiting of an intractable nature and profuse ptyalism, so much so that her face was swollen and the skin in the mouth region was raw with the irritation of the spittle. She had already lost three pregnancies on account of this condition. I tried a few standard remedies-mist. bis co., chloretone in capsule, etc.-without success. Then I gave her 20 drops of $25 \%$ benzyl benzoate in $90 \%$ alcohol, taken in water every two hours for three doses, and then every four hours. The effect was miraculous, and when I saw the patient the next day I did not recognize her, as the face was quite normal, only showing the burnt areas at the corners of the mouth. The ptyalism vanished with the first dose, and the vomiting also ceased. She had to continue taking the drug three times a day throughout the carrying period, as the condition recurred as soon as she stopped it. In the end she had a normal son, and everyone was happy.

\section{Nocturnal Cramp}

Dr. Simonds Gooding (Grays) writes: With reference to your correspondent's inquiry (Aug. 18, p. 240) about the prevention of noc:urnal cramp, it may be of interest to him to know that following an attack of acute gluteal fibrositis I personally suffered with very acute aitacks of nocturnal cramp in the calf muscles of the right leg. To remain in bed during an attack was quite.impossible owing to the severity of the pain. Various preparations of morphine and codeine, nembutal, allonal, amytal, antipyrine, etc., all proved quite ineffectual. On the advice of my colleague, Mr. L. Casin, F.R.C.S. I finally tried prostigmin, taking half a $15-\mathrm{mg}$. tablet each night on retiring to bed. I derived considerable relief from this drug, which, though probably not a cure, certainly relieved the symptoms and made the nights more bearable.

\section{Venereology}

Lieut.-Col. Henry Richards writes: In Army medical jargon a venereologist is an officer with a special knowledge of the diagnosis and treatment of venereal diseases. I have been hoping that some classical scholar would register an authoritative protest against the use of the word in this sense. The persistence of the term would be a regrettable addition to medical nomenclature. In the first place $\sigma$ the word is a hybrid, derived from Latin and Greek. Secondly, the word cannot possibly have the meaning now fastened to it. Venereologist can only mean a person with a knowledge of venery. An expert practitioner of the arts of love is not necessarily a specialist in the care of venereal diseases.

\section{An Unusual Cause of Intestinal Obstruction in a Newborn Baby $\frac{\mathscr{\omega}}{0}$}

Dr. H. R. UNwin (Yeovil) writes: The following unusual case occurred recently in my practice. A baby boy 4 days old had not $\overline{\bar{s}}$ passed any meconium since birth and was starting to vomit. An examination of the rectum by the little finger showed that it was normal as far as could be reached, and no meconium was found on the examining finger. Gastric peristalsis was visible after feeds, but ${ }^{\text {s }}$ it was only on the fourth day that vomiting became a feature of the $\overrightarrow{0}$ case. A laparotomy was performed and the following state of affairswas found. Torsion of the caecal end of the ileum had taken place $\vec{\omega}$ through three complete turns. This had been made possible by ao deficiency in the mesentery. Aseptic gangrene of the terminal 12 incheso of the ileum had resulted, with section of the ileum at the upper limit of the gangrene, the ends of the divided intestine being comiv pletely occluded. The ileum above the section was very distended for $\mathrm{A}$ about 6 inches. The treatment adopted was resection of the gangren $\frac{\vec{N}}{\mathrm{~N}}$ ous and distended ileum with an end-to-side ileo-caecostomy. The baby lived for two days after the operation and then died with symptoms of unrelieved obstruction. No post-mortem examination $\vec{A}$ was performed. It is probable that a paralytic ileus developed.

\section{Anatomical Nomenclature}

Mr. A. Hollman writes from University College Hospital: Surely it is time that surgeons in general, and the authors of surgicap anatomy books in particular, made an attempt to use the B.R nomenclature. At present the student learns his anatomy in term\& of the B.R. and then, on entering hospital, he has the further burdemD of learning obsolete synonyms. If this state of affairs were rectified it would materially ease the student's task of learning what is, any way, an uninspiring subject.

\section{Sleep-walking}

Dr. M. N. PaI writes: Some suggestions have appeared in the Journal on the treatment of sleep-walking. The causes of sleepo walking may be classified as follows: (1) Psychogenic or partia出 sleep dud to $(a)$ anxiety states, or $(b)$ genuine dissociation-e.g. $\Phi$ hysteria. When not sleep-walking a patient often talks or shouts in his sleep. Sometimes he may open the door and walk a long distance before waking up. (2) Post-epileptic: (a) following a noc3 turnal fit, or $(b)$ as an epileptic equivalent (instead of a fit). Hers the patient usually gets up from his bed and almost immediatel returns to it, or gets into another one if one is available. He seldom. walks more than a few yards. A positive E.E.G. may confirm the diagnosis, but a negative one does not exclude epilepsy. (3) Hysteroß malingering. Here, apart from walking, the patient carries out very complicated actions requiring careful thought and previous planning There is always an immediate gain. Careful observation at nighe hypnosis, or narco-analysis may help in the diagnosis. (4) Posti infective following meningitis, encephalitis lethargica, and chroni cerebral abscess. Here the patient may wander aimlessly in an apparently confused state. Other signs and symptoms help in the diagnosis. Treatment: ( 1 a $)$ relieve the anxiety or give large doses of sedative at night ; $\left(\begin{array}{ll}1 & b\end{array}\right)$ psychotherapy and suggestion-e.gQ hypnosis. (2) Epanutin at bedtime. 3 and 4 are difficult to trea

\section{Hospitals Day, Oct. 2}

The Secretary of the London Hospitals Street Collections Centrat Committee writes: May I call attention to the first street collectio in aid of London's hospitals since the coming of peace? Hospitas Day will be on Tuesday, Oct. 2. Collectors are urgently needed, and volunteers should offer their services to their nearest voluntang hospital or to Lord Luke, Chairman, Hospitals Day, 36, Kingswa凂 W.C.2.

\section{Corrections}

In the question and answer headed "Profuse Periods in a Your Girl," published in the Journal of Sept. 15, p. 374, the dosage of thyroid was given in error as 1 .gramme daily. This should ha read 1 grain.

In the question and answer on "Oil-in-water and Water-in-ol Emulsions" (Sept. 15, p. 374), it was said " the bivalent alkaline earths and trivalent gases invariably give rise to water-in-oil emu sions." This should have read, "trivalent bases."

In a question and answer discussing the use of tryparsamide G.P.I. (Sept. 15, p. 374) it was said that bismuth and arsenic may be given "concurrently or alternatively." This should have read " concurrently or alternately." 